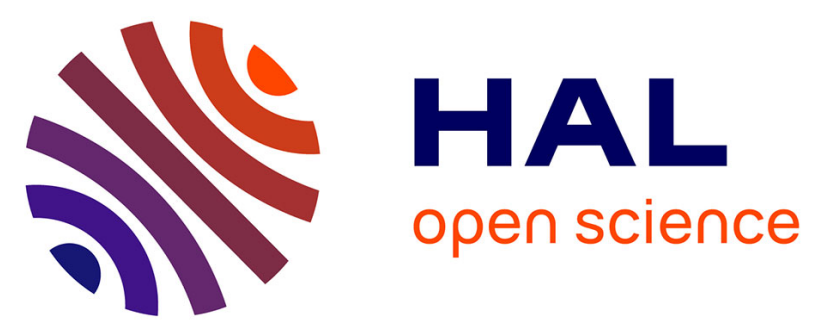

\title{
Saxagliptin is non-inferior to glipizide in patients with type 2 diabetes mellitus inadequately controlled on metformin alone: a 52-week randomised controlled trial Ingrid Gause-Nilsson, Burkhard Göke, Baptist Gallwitz, Johan Eriksson, Asa Hellqvist
}

\section{To cite this version:}

Ingrid Gause-Nilsson, Burkhard Göke, Baptist Gallwitz, Johan Eriksson, Asa Hellqvist. Saxagliptin is non-inferior to glipizide in patients with type 2 diabetes mellitus inadequately controlled on metformin alone: a 52-week randomised controlled trial. International Journal of Clinical Practice, 2010, 64 (12), pp.1619. 10.1111/j.1742-1241.2010.02510.x . hal-00577009

\section{HAL Id: hal-00577009 \\ https://hal.science/hal-00577009}

Submitted on 16 Mar 2011

HAL is a multi-disciplinary open access archive for the deposit and dissemination of scientific research documents, whether they are published or not. The documents may come from teaching and research institutions in France or abroad, or from public or private research centers.
L'archive ouverte pluridisciplinaire HAL, est destinée au dépôt et à la diffusion de documents scientifiques de niveau recherche, publiés ou non, émanant des établissements d'enseignement et de recherche français ou étrangers, des laboratoires publics ou privés. 


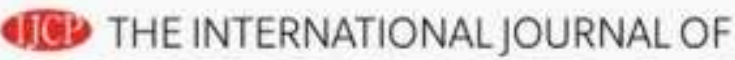 CLINICAL PRACTICE}

\section{Saxagliptin is non-inferior to glipizide in patients with type 2 diabetes mellitus inadequately controlled on metformin alone: a 52-week randomised controlled trial}

\begin{tabular}{|c|c|}
\hline Journal: & International Journal of Clinical Practice \\
\hline Manuscript ID: & IJCP-07-10-0351.FX5.R1 \\
\hline Wiley - Manuscript type: & EXPEDITED Clinical Trial - \$1500 \\
\hline $\begin{array}{r}\text { Date Submitted by the } \\
\text { Author: }\end{array}$ & 05-Aug-2010 \\
\hline Complete List of Authors: & $\begin{array}{l}\text { Gause-Nilsson, Ingrid; AstraZeneca R\&D Mölndal } \\
\text { Göke, Burkhard; Hospital of the Ludwig Maximilian } \\
\text { Gallwitz, Baptist; Tuebingen University, Department of Medicine IV } \\
\text { Eriksson, Johan; Helsinki University Central Hospital, Unit of } \\
\text { General Practice } \\
\text { Hellqvist, Asa; AstraZeneca R\&D Mölndal }\end{array}$ \\
\hline Specialty area: & \\
\hline
\end{tabular}

\section{SCHOLARONE ${ }^{\mathrm{m}}$ Manuscripts}


Manuscript ID IJCP-07-10-0351.FX5

Original Paper

Saxagliptin is non-inferior to glipizide in patients with type 2 diabetes mellitus inadequately controlled on metformin alone: a 52-week randomised controlled trial

$<<$ Short Title >>

Saxagliptin non-inferior to glipizide as add-on therapy to metformin

$<<$ Authors $>>$

B. Göke, ${ }^{1}$ B. Gallwitz, ${ }^{2}$ J. Eriksson, ${ }^{3}$ Å. Hellqvist, ${ }^{4}$ I. Gause-Nilsson, ${ }^{4}$ for the D1680C0001 Investigators

$<<$ Affiliations $>>$

${ }^{1}$ Hospital of the Ludwig Maximilian, University of Munich, Munich, Germany

${ }^{2}$ Klinikum der Eberhard-Karls-Universität Tübingen Medizinische Klinik, Tübingen, Germany

${ }^{3}$ Helsinki University Central Hospital, Unit of General Practice and University of Helsinki, Helsinki, Finland

${ }^{4}$ AstraZeneca Research \& Development, Mölndal, Sweden

Correspondence to:

Ingrid Gause-Nilsson

AstraZeneca R\&D Mölndal

S-431 83 Mölndal, Sweden

Tel.: + 46317763769

Fax: + 46317762602

Email: Ingrid.Gause-Nilsson@astrazeneca.com

\section{Disclosures:}

Drs Göke and Eriksson declare no conflicts of interest. Dr Gallwitz has served on advisory boards for AstraZeneca, Bristol-Myers Squibb, Boehringer Ingelheim, Eli Lilly and Company, Novartis, Novo Nordisk, Merck \& Co., Inc., Hoffman-La Roche Inc., and Takeda Pharmaceutical, and received honoraria for speaking engagements from these companies. Åsa Hellqvist, MSc, and Dr Gause-Nilsson are employees of AstraZeneca Research \& Development.

Key Words: add-on therapy, dipeptidyl peptidase-4, DPP-4, $\mathrm{HbA}_{1 \mathrm{c}}$, incretin, non-inferiority, sulphonylurea, glipizide, saxagliptin, type 2 diabetes mellitus, T2DM

Summary word count (limit 250): 262 words (exclusive of headers and trial reg info) Article word count (no limit): 4596 words (exclusive of What's known and What's new sections, data slugs, abstract, acknowledgements, references, tables and figures, table and figure legends) 
Manuscript ID IJCP-07-10-0351.FX5

SUMMARY (Current word count: 262 exclusive of headers and trial reg info)

\begin{abstract}
Aim: Assess the efficacy and safety of saxagliptin vs. glipizide, as add-on therapy to metformin in patients with type 2 diabetes mellitus and inadequate glycaemic control on metformin alone.

Methods and patients: A total of 858 patients (age $\geq 18$ years; glycated haemoglobin $\left[\mathrm{HbA}_{1 \mathrm{c}}\right]>6.5-$ $10.0 \%$; on stable metformin doses $\geq 1500 \mathrm{mg} /$ day) were randomised $1: 1$ to saxagliptin $5 \mathrm{mg} /$ day or glipizide up-titrated as needed from 5-20mg/day for 52 weeks. The primary objective was to assess if the change from baseline $\mathrm{HbA}_{1 \mathrm{c}}$ achieved with saxagliptin plus metformin was non-inferior to glipizide plus metformin.
\end{abstract}

Results: The per-protocol analysis demonstrated non-inferiority of saxagliptin vs. glipizide; adjusted mean changes from baseline $\mathrm{HbA}_{1 \mathrm{c}}$ were $-0.74 \%$ vs. $-0.80 \%$, respectively; the between-group difference was $0.06 \%$ (95\% CI, -0.05 to $0.16 \%$ ). Treatment with saxagliptin vs. glipizide was associated with significantly fewer proportion of patients with hypoglycaemic events $(3.0 \%$ vs. $36.3 \% ; \mathrm{p}<0.0001)$ and a divergent impact on body weight (adjusted mean change from baseline $-1.1 \mathrm{~kg}$ with saxagliptin vs. $1.1 \mathrm{~kg}$ with glipizide; $\mathrm{p}<0.0001)$. There was a significantly smaller rise in $\mathrm{HbA}_{1 \mathrm{c}}(\% / \mathrm{wk})$ from week 24 to 52 with saxagliptin vs. glipizide $(0.001 \%$ vs. $0.004 \%$; $=0.04)$ indicating a sustained glycaemic effect beyond week 24. Excluding hypoglycaemic events, the proportion of patients experiencing adverse events (AEs) was similar (60.0\% saxagliptin vs. $56.7 \%$ glipizide); treatment-related AEs were less common with saxagliptin vs. glipizide (9.8\% vs. $31.2 \%)$, attributable to the higher frequency of hypoglycaemia in glipizide patients. Discontinuation rates due to AEs were similar ( 4\%).

Conclusion: Saxagliptin plus metformin provided a sustained $\mathrm{HbA}_{1 \mathrm{c}}$ reduction over 52 weeks and was non-inferior to glipizide plus metformin, with reduced body weight and significantly lower risk of hypoglycaemia.

Trial Registration ClinicalTrials.gov ID No.: NCT00575588. 
Manuscript ID IJCP-07-10-0351.FX5

1

2

3

4

5

6

7

8

9

10

11

12

13

14

15

16

17

18

19

20

21

22

23

24

25

26

27

28

29

30

31

32

33

34

35

36

37

38

39

40

41

42

43

44

45

46

47

48

49

50

51

52

53

54

55

56

57

58

59

60

What's known (70 words max; current word count: 57 words)

- Due to insulin resistance and the progressive beta-cell failure that characterises type 2 diabetes mellitus, most patients will eventually require combination therapy to achieve and maintain adequate glycaemic control.

- Combination therapy with metformin and a sulphonylurea is a common therapeutic strategy; however, sulphonylureas are associated with treatment-limiting side effects, such as weight gain and hypoglycaemia.

What's new (70 words max; current word count without data slug: 68 words)

- This non-inferiority trial assessed the efficacy and safety of saxagliptin $5 \mathrm{mg}$ vs. glipizide, as add-on therapy to metformin for 52 weeks in patients with type 2 diabetes mellitus and inadequate glycaemic control on metformin alone.

- Saxagliptin provided a sustained $\mathrm{HbA}_{1 \mathrm{c}}$ reduction over 52 weeks and was non-inferior to glipizide in lowering $\mathrm{HbA}_{\mathrm{lc}}$ with reduced body weight and significantly lower risk of hypoglycaemia compared with glipizide. 
Manuscript ID IJCP-07-10-0351.FX5

\section{Introduction}

Failure to achieve and maintain adequate glycaemic control is due to the progressive nature of type 2 diabetes mellitus (T2DM) (1) and the limitations of current therapies (2-4). Achieving glycaemic goals can substantially reduce morbidity, making effective treatment of hyperglycaemia a high priority (5). Insulin resistance and a decreasing number of functional insulin-producing beta-cells contribute to the pathophysiology of T2DM and, thus, most patients eventually require combination therapy (6-8). Treatments targeting the beta-cell dysfunction that characterises T2DM, as well as other underlying disease mechanisms are necessary to achieve and maintain normal glucose levels over time (7). Moreover, some current therapies have treatment-limiting side effects, including hypoglycaemia and weight gain (9). Combining therapeutic agents that differ in their mechanism of action and tolerability profiles can address some of these treatment challenges (10).

Metformin is standard first-line pharmacotherapy for patients with T2DM (3,10). Metformin is inexpensive, generally well tolerated and infrequently associated with hypoglycaemia, though dosing may be limited by transient gastrointestinal effects $(1,3)$. The major non-glycaemic benefit of metformin is weight stability or modest weight loss, in contrast with many other blood glucose-lowering medications, such as sulphonylurea or insulin $(3,9)$. As monotherapy, metformin typically results in glycated haemoglobin $\left(\mathrm{HbA}_{1 c}\right)$ reductions of $1.0 \%$ to $2.0 \%$ depending on baseline $\operatorname{HbA}_{1 \mathrm{c}}(1,11,12)$; however, metformin alone is frequently insufficient to maintain glycaemic goals over time $(8,13)$.

Sulphonylureas are commonly used as add-on therapy in patients with inadequate glycaemic control on metformin alone and represent current standard therapy in most T2DM treatment algorithms $(3,14,15)$. Sulphonylureas are also inexpensive and initially demonstrate strong $\mathrm{HbA}_{1 \mathrm{c}}$-lowering effects $(3,14)$. Their use, however, is associated with limitations, which include multiple titration steps, the potential for betacell failure (6,16), weight gain (15) and increased risk of hypoglycaemia (17). Hypoglycaemia in 
Manuscript ID IJCP-07-10-0351.FX5

1

2

3

4

5

6

7

8

9

particular affects morbidity and quality of life for patients with T2DM and is a major obstacle to medication adherence $(18,19)$.

Dipeptidyl peptidase-4 (DPP-4) inhibitors are a relatively new class of oral antidiabetic agents (OADs) and augment glucose homoeostasis by preventing degradation of the incretin hormones, glucagon-like peptide-1 (GLP-1) and glucose-dependent insulinotropic peptide (GIP) $(1,4)$. The former hormone accounts for the majority of the incretin effect and is a key component in regulating both fasting plasma glucose (FPG) and postprandial glucose (PPG) by stimulating glucose-dependent insulin secretion, and attenuating glucagon secretion by the pancreatic alpha-cells to decrease glucose production by the liver $(1,4,20)$. DPP-4 inhibitors demonstrate a low propensity for hypoglycaemia and are generally weight neutral, making them suitable candidates for combination therapy $(4,19)$. Further, metformin works through pathways complementary to DPP-4 inhibitors, and combination therapy may improve glycaemic control by targeting multiple mechanisms (21) without increasing the risk of hypoglycaemia or inducing weight gain.

Saxagliptin is a selective DPP-4 inhibitor approved as an adjunct to diet and exercise for the management of glycaemic control in adults with T2DM $(22,23)$. Saxagliptin, either as add-on therapy to metformin or given with metformin as initial therapy for 24 weeks was well tolerated and led to statistically significant improvements in glycaemic indices vs. placebo and metformin, respectively, in patients with T2DM and inadequate glycaemic control $(24,25)$. Hypoglycaemic events were comparable across treatment groups and there were no increases in weight observed in the saxagliptin plus metformin groups in either study (24,25). Additionally, saxagliptin and metformin combination therapy improved indices of beta-cell function (24). Combination therapy with saxagliptin and metformin may offer several advantages compared with the current standard practice of metformin-sulphonylurea combination therapy. 
Manuscript ID IJCP-07-10-0351.FX5

This 52-week trial assessed the efficacy and safety of saxagliptin vs. the sulphonylurea, glipizide, as addon therapy to metformin in patients with T2DM and inadequate glycaemic control on a stable dose of metformin alone. A non-inferiority trial design was chosen to investigate the clinical equivalence of saxagliptin plus metformin therapy as compared with the current standard treatment of sulphonylurea plus $\underline{\text { metformin. }}$

\section{Patients and methods}

\section{Patients}

Eligible study participants were men and women age $\geq 18$ years with $\mathrm{T} 2 \mathrm{DM}$ and $\mathrm{HbA}_{1 \mathrm{c}}>6.5 \%-10.0 \%$ on a stable dose of metformin monotherapy $\geq 1500 \mathrm{mg} /$ day for at least 8 weeks prior to enrollment. Key exclusion criteria included type 1 diabetes; history of diabetic ketoacidosis or hyperosmolar non-ketotic coma; insulin therapy within 1 year of enrollment; treatment with a thiazolidinedione within the 12 weeks prior to enrollment; treatment with systemic glucocorticoids other than replacement therapy; previous DPP-4 inhibitor treatment; donation of blood, plasma or platelets within the 3 months prior to enrollment; congestive heart failure defined as New York Heart Association class III or IV and/or known left ventricular ejection fraction $\leq 40 \%$; significant cardiovascular $(\mathrm{CV})$ history within the past 6 months defined as myocardial infarction, coronary angioplasty or bypass graft(s), valvular disease or repair, unstable angina pectoris, transient ischaemic attack or cerebrovascular accident; history of haemoglobinopathies; significant alcohol or drug abuse within the year prior to enrollment; treatment with human immunodeficiency virus/antiviral drugs or cytochrome P450 3A4 (CYP450 3A4) inducers; serum creatinine $\geq 1.5 \mathrm{mg} / \mathrm{dL}[\geq 133 \mu \mathrm{mol} / \mathrm{L}$ (men)]; $\geq 1.4 \mathrm{mg} / \mathrm{dL}[\geq 124 \mu \mathrm{mol} / \mathrm{L}$ (women)]; active liver disease and/or significant abnormal liver function [aspartate aminotransferase (AST) $>2 \times$ upper limit of normal (ULN) and/or alanine aminotransferase (ALT) $>2 \times$ ULN and/or total bilirubin $>2.0 \mathrm{mg} / \mathrm{dL}(>34$ $\mu \mathrm{mol} / \mathrm{L})]$ or any clinically significant laboratory abnormality upon screening. 
Manuscript ID IJCP-07-10-0351.FX5

The study protocol was approved by the Institutional Review Board/Independent Ethics Committee for each participating site, and carried out in accordance with the Declaration of Helsinki and International Conference on Harmonisation/Good Clinical Practice guidelines. Patients were informed of the study purpose and potential risks, and gave written informed consent.

\section{Study design}

This was a 52-week, phase 3b, international, multicenter, randomised, parallel-group, active-controlled, double-blind, non-inferiority trial, with a 52-week extension period (ongoing). Eligible patients enrolled in a 2-week, single-blind, placebo-controlled lead-in period that included advice on diet and exercise. All patients received open-label metformin at $1500,2000,2500$ or $3000 \mathrm{mg}$ daily based on individual metformin dose at enrollment for the duration of the study; the dose remained stable throughout the study. Patients were assigned a glucometer and patient diary for the course of the initial 52-week treatment period and instructed to monitor their fingerstick glucose level regularly. Information about hypoglycaemic events (list of symptoms, fingerstick value if obtained) was to be entered into the patient diary.

At screening, patients were assigned a unique identifier to be used throughout the study. Following the lead-in period, eligible patients were randomised (1:1) via an interactive Web-response system using a balanced block randomisation schedule to 1 of 2 treatment groups: saxagliptin $5 \mathrm{mg} /$ day plus open-label metformin or glipizide up-titrated as needed from 5 to $20 \mathrm{mg} /$ day plus open-label metformin. Blinding was ensured using a double-dummy technique. Study medication was taken orally, immediately before or with a meal.

Patients assigned to saxagliptin plus metformin remained on saxagliptin $5 \mathrm{mg}$ throughout the study. For patients assigned glipizide plus metformin, glipizide was titrated to an optimal effect (FPG $\leq 110 \mathrm{mg} / \mathrm{dl}$ $[\leq 6.1 \mathrm{mmol} / \mathrm{l}])$ or the highest tolerated dose during an 18 -week titration period. Glipizide was initiated at 
Manuscript ID IJCP-07-10-0351.FX5

$5 \mathrm{mg} /$ day (morning dose) and titrated in 3-week intervals to a maximum of $20 \mathrm{mg} /$ day using a doubledummy technique to ensure blinding. Titration steps were $10 \mathrm{mg} /$ day (morning dose), followed by 15 $\mathrm{mg} /$ day (10 mg morning dose, $5 \mathrm{mg}$ evening dose) and $20 \mathrm{mg} /$ day (10 mg morning dose, $10 \mathrm{mg}$ evening dose). Initial titration assessment was at week 3; subsequent re-assessment for titration occurred at weeks $6,9,12,15$ and 18 . During the titration period, glipizide could be down-titrated once if hypoglycaemic events occurred and could thereafter be up-titrated once. Evaluation at each titration visit and final decision by the investigator on dose increase or decrease took into account patient glucose measurements made before visits, hypoglycaemic events recorded in the patient diary and investigator's measurements at titration visits. Following the titration period, medication doses remained stable except for instances of glipizide down-titration to mitigate recurrent hypoglycaemia at the discretion of the study investigator; no up-titration was allowed. Patients were instructed to monitor their fingerstick glucose levels at least once a week and continue documenting hypoglycaemic events in their patient diaries.

Throughout the study, patients were discontinued if they failed to meet prespecified, progressively more stringent glycaemic control criteria. Patients with FPG $>270 \mathrm{mg} / \mathrm{dl}(>15.0 \mathrm{mmol} / \mathrm{l}),>240 \mathrm{mg} / \mathrm{dl}(>13.3$ $\mathrm{mmol} / \mathrm{l}),>220 \mathrm{mg} / \mathrm{dl}(>12.2 \mathrm{mmol} / \mathrm{l})$ or $>200 \mathrm{mg} / \mathrm{dl}(11.1 \mathrm{mmol} / \mathrm{l})$ at weeks $3,12,18$ or 24 , respectively, or $\mathrm{HbA}_{1 \mathrm{c}}>8.0 \%$ at week 30 or 39 were discontinued. Assessments took place at each visit to determine if study discontinuation criteria were met. 
Manuscript ID IJCP-07-10-0351.FX5

\section{Study end-points}

The primary efficacy end-point was change from baseline to week 52 in $\mathrm{HbA}_{1 \mathrm{c}}$ and was used to assess if saxagliptin plus metformin was non-inferior to glipizide plus metformin. Key secondary end-points were the proportion of patients reporting $\geq 1$ event of hypoglycaemia over 52 weeks, the change from baseline body weight at week 52 and the mean slope of regression of change from week 24 to week $52 \mathrm{in} \mathrm{HbA}_{1 \mathrm{c}}$. Other secondary end-points included change from baseline FPG, fasting insulin, C-peptide, glucagon and proinsulin; the proportion of patients achieving a therapeutic glycaemic response defined as $\mathrm{HbA}_{\mathrm{lc}} \leq$ $6.5 \% ; \mathrm{HbA}_{1 \mathrm{c}}$ change from baseline in patients with baseline $\mathrm{HbA}_{1 \mathrm{c}} \geq 7.0 \%$; the proportion of patients achieving a therapeutic glycaemic response defined as $\mathrm{HbA}_{1 \mathrm{c}}<7.0 \%$ in patients with baseline $\mathrm{HbA}_{1 \mathrm{c}} \geq$ 7.0\%, and change from baseline beta-cell function (as measured by homeostasis model assessment [HOMA-2 $\beta$ ]). Change from baseline to week 52 in 120-minute PPG during an oral glucose tolerance test (OGTT) was also assessed in a subset of patients.

Safety and tolerability assessments included adverse events (AEs), serious AEs (SAEs), related AEs, discontinuations from study medication due to AEs and deaths, as well as AEs of special interest, specifically hypoglycaemia, lymphopenia, thrombocytopenia, skin disorders, localised oedema, infections and CV AEs. Laboratory values, electrocardiograms, vital signs, physical examination and body weight were also assessed. 
Manuscript ID IJCP-07-10-0351.FX5

\section{Statistical analyses}

The primary efficacy analysis and key secondary efficacy analyses involving $\mathrm{HbA}_{1 \mathrm{c}}$ were conducted on a per-protocol (PP) analysis set. The PP analysis set included patients who completed the 52-week randomised treatment period, had both a baseline and week $52 \mathrm{HbA}_{\mathrm{lc}}$ measurement and no significant protocol deviations. The full analysis set, which included all patients who received at least 1 dose of randomised study medication and had at least 1 non-missing baseline and 1 post-baseline efficacy data assessment, was used for confirmatory analysis of the primary end-point and for all other efficacy analyses.

Efficacy analyses for continuous variables were performed using an analysis of covariance (ANCOVA) model, with treatment as an effect and baseline $\mathrm{HbA}_{1 \mathrm{c}}$ as the covariate. Within the framework of the ANCOVA model, point estimates and 95\% confidence intervals (CIs) for the mean change within each treatment group, as well as for the differences in mean change between the saxagliptin plus metformin group and the glipizide plus metformin group were estimated. Saxagliptin plus metformin was considered non-inferior to glipizide plus metformin if the upper limit of the $95 \% \mathrm{CI}$ of the difference in change in $\mathrm{HbA}_{1 \mathrm{c}}$ from baseline to week 52 between the 2 treatment groups was $<0.35 \%$. A fixed-sequence test was employed for primary and key secondary efficacy end-points to control the overall type I error rate of the study. All comparisons were 2 -sided at the $5 \%$ significance level. The proportion of patients reporting $\geq 1$ hypoglycaemic event and the percentage of patients achieving a targeted glycaemic response were analysed using the Fisher exact test. A mixed model with patient-specific slopes using observed values assessed the durability of the $\mathrm{HbA}_{1 \mathrm{c}}$ effect.

Demographic and other baseline characteristics were summarised using descriptive statistics. Secondary end-point analyses and analysis by categorical baseline $\mathrm{HbA}_{1 \mathrm{c}}$ subgroup was prespecified. A conversion chart of conventional to Système International d'Unités is provided in Supplementary Table 1. 
Manuscript ID IJCP-07-10-0351.FX5

1

2

3

4

5

6

7

8

9

All patients who received at least 1 dose of study medication during the 52-week treatment period were included in the safety analysis (safety analysis set). Patients were assessed for safety according to the actual treatment taken. AEs were tabulated; other safety-related variables were summarized using descriptive statistics, tabulations and/or listings. AEs were classified according to the Medical Dictionary for Regulatory Activities (MedDRA) version 12.0 at the preferred term (PT) level and grouped by system organ class (SOC). AEs of special interest were identified by matching reported AEs to a predefined list of PTs or lowest level terms (localised oedema only) reflective of that particular diagnosis. AE intensity was defined as mild (awareness of event but easily tolerated), moderate (discomfort enough to cause some interference with usual activity), severe (inability to carry out usual activity) or very severe (debilitating, significantly incapacitates patient despite symptomatic therapy). Reported hypoglycaemia events were a combination of reports of either signs or symptoms consistent with hypoglycaemia with or without documented glucose levels or reported low glucose levels without any symptoms. Confirmed hypoglycaemia was defined as fingerstick glucose value $\leq 50 \mathrm{mg} / \mathrm{dl}(\leq 2.8 \mathrm{mmol} / \mathrm{l})$ with associated symptoms.

With 419 patients per treatment group, there was a $95 \%$ power to establish the non-inferiority comparison on change from baseline to week 52 in $\mathrm{HbA}_{\mathrm{lc}}$ at the $5 \%$ level, assuming that the standard deviation (SD) of change from baseline in $\mathrm{HbA}_{1 c}$ was $1.1 \%$, with a non-inferiority limit set at $0.35 \%$ and a zero true difference between the 2 randomised treatments. The sample size assumed that $35 \%$ of randomised patients would be excluded from the PP analysis set.

\section{Results}

Disposition, baseline demographics, clinical characteristics, and drug exposures A total of 858 patients were randomised and treated with double-blind therapy; 633 (73.8\%) completed the 52-week treatment period, with comparable completion percentages between groups ( $72.9 \%$ for saxagliptin plus metformin, $74.7 \%$ for glipizide plus metformin) (Figure 1). Demographic and baseline 
Manuscript ID IJCP-07-10-0351.FX5

clinical characteristics were generally well balanced across treatment groups in both the randomised and PP analysis sets and representative of patients with uncontrolled T2DM treated with metformin monotherapy (Table 1). For the overall study population, mean age, $\mathrm{HbA}_{1 \mathrm{c}}$, weight, body mass index (BMI), metformin dose and duration of T2DM were 57.6 years, $7.7 \%, 88.7 \mathrm{~kg}, 31.4 \mathrm{~kg} / \mathrm{m}^{2}, 1910 \mathrm{mg} / \mathrm{day}$ and 5.4 years, respectively. Mean final glipizide total daily dose (TDD) was $14.7 \mathrm{mg} / \mathrm{day}$ (range, 0-20 $\mathrm{mg}$ ); more than two-thirds of patients in the glipizide plus metformin group underwent 2 or more dose titrations, and approximately $50 \%$ of the patients in the glipizide plus metformin group reached a final glipizide TDD of $20 \mathrm{mg} /$ day. Median exposure to study medication was 363 days for the saxagliptin plus metformin group and 364 days for the glipizide plus metformin group.

A total of 59 patients were enrolled for an OGTT; however, the number of evaluable OGTT results was low (35 patients).

\section{Primary end-point}

At 52 weeks, saxagliptin plus metformin was non-inferior to glipizide plus metformin in lowering $\mathrm{HbA}_{1 \mathrm{c}}$ (primary analysis of the PP analysis set). Adjusted mean changes from baseline $\mathrm{HbA}_{1 \mathrm{c}}$ were $-0.74 \%$ vs. $0.80 \%$ with saxagliptin vs. glipizide, respectively; the between-group difference was $0.06 \%$ (95\% CI, $0.05 \%$ to $0.16 \%$ ) (Figure $2 \mathrm{~A}$, Table 2 ). Confirmatory analysis of the full analysis set yielded consistent results (adjusted mean change from baseline $\mathrm{HbA}_{1 \mathrm{c}}-0.57 \%$ vs. $-0.66 \%$ for saxagliptin plus metformin vs. glipizide plus metformin, respectively). Mean $\mathrm{HbA}_{1 \mathrm{c}}$ values over time for the PP analysis set are shown in Figure 2B.

Key secondary end-points

The proportion of patients reporting $\geq 1$ hypoglycaemic event over 52 weeks was low in the saxagliptin plus metformin group (3.0\%), and was significantly lower compared with the glipizide plus metformin 
Manuscript ID IJCP-07-10-0351.FX5

group $(36.3 \%$ ) (difference vs. glipizide plus metformin $-33.2 \%$ (95\% CI, $-38.1 \%$ to $-28.5 \%$; $p<0.0001$ )

(Figure 3).

Treatment with saxagliptin vs. glipizide was associated with a divergent impact on body weight at week 52 ; mean body weight decreased in the saxagliptin plus metformin group and increased in the glipizide plus metformin group. Adjusted mean changes from baseline were $-1.1 \mathrm{~kg}$ vs. $1.1 \mathrm{~kg}$, with saxagliptin vs. glipizide respectively; the between-group difference was $-2.2 \mathrm{~kg}(95 \% \mathrm{CI},-2.7$ to $-1.7 ; \mathrm{p}<0.0001)$

(Figure 4).

The PP analysis demonstrated a small rise per week in $\mathrm{HbA}_{1 \mathrm{c}}$ during weeks 24 to 52 in both treatment groups (mean changes per week $0.001 \%$ for saxagliptin and $0.004 \%$ for glipizide). The rise per week was statistically significantly smaller with saxagliptin vs. glipizide $(-0.002 \%$ difference, $95 \% \mathrm{CI},-0.0046 \%$ to $-0.0001 \% ; \mathrm{p}=0.04$ ) indicating a more sustained effect on glycaemic control beyond week 24 .

Other secondary end-points

Changes in other secondary efficacy variables from baseline to week 52 are listed in Table 2. Both treatment groups demonstrated improved glycaemic control as assessed by decreases from baseline FPG, with a numerically greater decrease with glipizide plus metformin vs. saxagliptin plus metformin. There were small and generally similar increases from baseline in both treatment groups in mean values for fasting insulin and fasting C-peptide. Numerical reductions in fasting proinsulin and numerically smaller increases in fasting glucagon were demonstrated for saxagliptin vs. glipizide.

The proportion of patients achieving $\mathrm{HbA}_{1 \mathrm{c}} \leq 6.5 \%$ was similar (35.9\% vs. $34.3 \%$ for saxagliptin vs. glipizide, respectively). The proportion of patients achieving $\mathrm{HbA}_{1 \mathrm{c}}<7.0 \%$ (with or without hypoglycaemic events) in patients whose baseline $\mathrm{HbA}_{1 \mathrm{c}} \geq 7.0 \%$ was similar (42.6\% vs. $47.8 \%$ for saxagliptin vs. glipizide, respectively). When patients with hypoglycaemic events were excluded, $41.4 \%$ 
Manuscript ID IJCP-07-10-0351.FX5

(saxagliptin) vs. 30.9\% (glipizide) of patients achieved $\mathrm{HbA}_{1 \mathrm{c}}<7.0 \%$. Greater decreases were associated with categories of higher baseline $\mathrm{HbA}_{1 \mathrm{c}}$ in each treatment group. Adjusted mean changes from baseline for saxagliptin vs glipizide, respectively, were -0.32 vs. -0.30 for $\mathrm{HbA}_{1 \mathrm{c}}<7.0 \% ;-0.45$ vs. -0.58 for $\mathrm{HbA}_{1 \mathrm{c}} \geq 7.0 \%$ to $<8.0 \% ;-0.84$ vs. -0.81 for $\mathrm{HbA}_{\mathrm{lc}} \geq 8.0 \%$ to $<9.0 \%$; and -1.05 vs. -1.72 for $\mathrm{HbA}_{1 \mathrm{c}} \geq$ 9.0\%. An interaction of treatment with baseline category was observed $(p=0.0179)$. The smallest subgroup analysed, ie, those with baseline $\mathrm{HbA}_{1 \mathrm{c}} \geq 9.0 \%,(\mathrm{n}=79)$ demonstrated numerically greater reductions with glipizide plus metformin vs. saxagliptin plus metformin (between-group difference $0.67 \%$ [ $95 \% \mathrm{CI}, 0.31 \%$ to $1.04 \%])$. and is likely to be the source of the significant interaction.

Patients treated with glipizide plus metformin had a greater mean increase in HOMA-2 $\beta$ vs. saxagliptin plus metformin. For the small OGTT patient subset, the saxagliptin plus metformin group demonstrated numerically greater decreases from baseline in 120-minute PPG vs. the glipizide plus metformin group

(data not shown).

Deleted: Table 2

Fifty-nine $(13.8 \%)$ patients in the saxagliptin plus metformin group and $47(10.9 \%)$ patients in the glipizide plus metformin group met prespecified glycaemic discontinuation criteria and discontinued from the study by week 52. A small but greater number of patients in the saxagliptin plus metformin group discontinued due to high FPG up to week 24 vs. the glipizide plus metformin group (3.5\% vs. 1.2\%, respectively). Post 24 weeks, when criteria were based on $\mathrm{HbA}_{1 \mathrm{c}}$ levels, discontinuation rates were similar (10.3\% for the saxagliptin group vs. $9.8 \%$ for the glipizide group).

\section{Safety and tolerability}

Overall, saxagliptin plus metformin was generally well tolerated (Table 3). Excluding hypoglycaemia, the proportion of patients with AEs was similar between groups (60.0\% saxagliptin vs. $56.7 \%$ glipizide). Treatment-related AEs were less common with saxagliptin vs. glipizide (9.8\% vs. $31.2 \%$ ) due to the higher frequency of hypoglycaemia in patients receiving glipizide. The majority of AEs in both treatment 
Manuscript ID IJCP-07-10-0351.FX5

1

2

3

4

5

6

7

8

9

10

groups were mild or moderate in intensity and discontinuation rates due to AEs were similar for saxagliptin vs. glipizide. Four deaths occurred during the study period (cardiac failure and head injury in the saxagliptin plus metformin group; ischaemic stroke and myocardial infarction in the glipizide plus metformin group), none of which was considered by study investigators to be treatment related.

Hypoglycaemic events are listed in Table 4. A total of $13(3.0 \%)$ patients in the saxagliptin plus metformin group experienced 19 hypoglycaemic events and $156(36.3 \%)$ patients in the glipizide plus metformin group experienced 750 hypoglycaemic events over the 52-week treatment period. No patients $(0 \%)$ experienced a hypoglycaemic event with fingerstick glucose $\leq 50 \mathrm{mg} / \mathrm{dL}[2.8 \mathrm{mmol} / \mathrm{l}] \mathrm{or}$ a confirmed hypoglycaemic event (defined as fingerstick glucose value $\leq 50 \mathrm{mg} / \mathrm{dl}[2.8 \mathrm{mmol} / \mathrm{l}] \mathrm{with}$ associated symptoms) in the saxagliptin plus metformin group vs. $38(8.8 \%)$ and $35(8.1 \%)$ of the patients in the glipizide plus metformin group, respectively. Most hypoglycaemic events were mild in intensity. One $(0.2 \%)$ patient in the saxagliptin plus metformin group and $62(14.4 \%)$ patients in the glipizide plus metformin group had hypoglycaemic events that were moderate in intensity. No $(0 \%)$ patients in the saxagliptin plus metformin group and $7(1.6 \%)$ patients in the glipizide plus metformin group had hypoglycaemic events that were severe. No patients in the saxagliptin plus metformin group required medical assistance for a hypoglycaemic event; $4(0.9 \%)$ patients experienced a non-serious hypoglycaemic AE requiring medical assistance in the glipizide plus metformin group.

Two or fewer patients in either treatment group had AEs of lymphopenia, thrombocytopenia, skin disorders or localised oedema. The proportion of patients with CV AEs was comparable for saxagliptin vs. glipizide (8 [1.9\%] vs 9 [2.1\%], respectively). A total of 3 patients had hypersensitivity AEs: 1 patient in the saxagliptin plus metformin group (SAE of hypersensitivity) and 2 patients in the glipizide plus metformin group (AE of drug hypersensitivity [ciprofloxacin] and SAE of laryngeal oedema). There were no AEs of pancreatitis in the saxagliptin plus metformin group; $1(0.2 \%)$ patient in the glipizide plus metformin group had 2 SAEs of pancreatitis. Small mean decreases from baseline in systolic and diastolic 
Manuscript ID IJCP-07-10-0351.FX5

blood pressure, respectively, occurred in the saxagliptin plus metformin $(-4.1$ and $-2.7 \mathrm{~mm} \mathrm{Hg})$ and glipizide plus metformin $(-1.2$ and $-1.1 \mathrm{~mm} \mathrm{Hg})$ treatment groups. There were no apparent differences between the saxagliptin plus metformin and glipizide plus metformin groups in change from baseline in mean values for fasting lipid parameters. There were no clinically relevant changes in electrocardiograms or clinically meaningful drug effects on any laboratory safety parameter.

\section{Discussion}

This study demonstrated that in patients with T2DM not achieving glycaemic control on stable doses of metformin, the addition of saxagliptin $5 \mathrm{mg} /$ day to metformin provided $\mathrm{HbA}_{1 \mathrm{c}}$ reduction that was sustained over 52 weeks. The $\mathrm{HbA}_{1 \mathrm{c}}$ reduction at week 52 was non-inferior to adding glipizide to metformin, with a decrease in body weight and statistically significantly lower proportion of patients with hypoglycaemia vs. glipizide. Both saxagliptin and titrated dosages of glipizide added to metformin improved glycaemic control, as assessed by decreases from baseline $\mathrm{HbA}_{1 \mathrm{c}}$ and FPG, as well as the proportion of patients achieving a therapeutic response. As is frequently observed with antihyperglycaemic agents, greater reductions in $\mathrm{HbA}_{1 c}$ were seen in patients with higher $\mathrm{HbA}_{1 c}$ values at baseline. Although both treatment groups showed a small rise in $\mathrm{HbA}_{1 \mathrm{c}}$ from week 24 to week 52, a smaller rise per week in $\mathrm{HbA}_{1 \mathrm{c}}$ during this time period was observed for saxagliptin plus metformin vs. glipizide plus metformin indicating a longer period of sustained glycaemic control with saxagliptin treatment. The findings that glipizide-treated patients had a transient greater decrease in $\mathrm{HbA}_{\underline{1 c}}$ at some time points in the first half of the study as well as a greater mean increase in HOMA-2 $\beta$ may be explained by the mechanism of action of a sulphonylurea agent to directly stimulate insulin secretion and is in agreement with findings in other studies $(26,27)$.

While the importance of long-term glycaemic control has been repeatedly demonstrated, achievement of treatment goals may be limited by adverse drug effects, most notably hypoglycaemia and weight gain associated with some OADs used to treat T2DM (17). The increased number of patients experiencing 
Manuscript ID IJCP-07-10-0351.FX5

1

2

3

4

5

hypoglycaemia is particularly relevant for treatment combinations that include sulphonylureas and/or insulin; however, treatment with saxagliptin provided added efficacy without safety issues (hypoglycaemia or weight gain). Specifically, treatment with glipizide resulted in 12 times as many patients with hypoglycaemic events relative to saxagliptin-treated patients.

Despite the fact that weight gain has been observed with intensive glycaemic control (9), saxagliptin treatment resulted in a small weight loss, compared to weight gain with sulphonylurea therapy. Results from 24-week studies of saxagliptin and metformin combination therapy have also demonstrated reductions from baseline body weight from- $-0.87 \mathrm{~kg}$ to $-1.8 \mathrm{~kg}(24,25)$. Because a majority of patients with T2DM are overweight or obese, therapeutic regimens that have a neutral or beneficial impact on weight are important in clinical practice.

Although firm conclusions cannot be drawn from comparisons between studies performed in different patient populations with different designs, the present results were comparable to those of a similar 52week study by Nauck et al using a DPP-4 inhibitor (sitagliptin) added to metformin compared with glipizide added to metformin. Sitagliptin $100 \mathrm{mg}$ /day plus metformin was noninferior to glipizide plus metformin $\left(\mathrm{HbA}_{1 \mathrm{c}}\right.$ change from baseline $-0.67 \%$, both groups); proportion of patients experiencing hypoglycaemia was significantly higher with glipizide vs. sitagliptin. Sitagliptin also demonstrated a small decrease in weight compared with with glipizide (26). Two-year study results were recently published and demonstrated similar glucose-lowering efficacy between completers in the 2 treatment groups, but with lower risk of hypoglycaemia and weight loss compared with weight gain with sitagliptin vs glipizide (28). Another DPP-4 inhibitor, vildagliptin, was also studied as an add-on to metformin therapy vs. the sulphonylurea glimepiride added on to metformin. Two year results indicated vildagliptin $50 \mathrm{mg}$ twice daily was noninferior to glimepiride $\left(\mathrm{HbA}_{1 \mathrm{c}}\right.$ change from baseline $-0.1 \%$, both groups), with fewer patients experiencing hypoglycaemia and a beneficial effect on body weight for vildagliptin vs glimepiride, respectively (29). In all studies, a greater proportion of patients treated with a DPP-4 
Manuscript ID IJCP-07-10-0351.FX5

inhibitor achieved target $\mathrm{HbA}_{1 \mathrm{c}}$ goals. These results, in addition to those of the current study, support the utility of DPP-4 inhibitor therapy added to metformin and suggest greater tolerability with comparable efficacy vs. the current standard practice of metformin-sulphonylurea combination therapy.

Given the common and increasing use of OADs, the relative impact on CV health is also of critical importance and a matter of much debate. Studies assessing the association of combination therapy of metformin and sulphonylureas on all-cause and/or cardiovascular mortality risk in T2DM are not consistent. There has been reported both a neutral CV risk (30,31), a decreased CV risk (32), and an increased CV risk (33-36). A recent evaluation of total CV death/myocardial infarction/stroke events in the pooled phase $2 / 3$ clinical trials of saxagliptin demonstrated no evidence of increased risk (37). Retrospective studies of other DPP-4 inhibitors (sitagliptin, vildagliptin) as monotherapy or in combination treatment suggest no increased risk of CV events (38-40). This favourable tolerability profile suggests that the addition of DPP-4 inhibitors to metformin may be appropriate and preferable for certain patients, including those who are overweight or at higher risk of hypoglycaemia.

There were some limitations to this study; it included mostly patients with uncomplicated T2DM at the time of metformin failure, thus limiting the ability to generalise safety findings across the broad range of patients with T2DM. However, the characteristics of the patient population recruited as well as the degree of $\mathrm{HbA}_{\underline{1 c}}$ reduction are well in line with other studies in patients with failure on metformin monotherapy and support the external validity of the study findings (41). The small sample size of the OGTT patient subset precluded definitive conclusions about PPG effects in this study. Reduction of PPG with saxagliptin in combination with metformin has been demonstrated in other studies $(24,25)$.

In summary, achieving specific glycaemic goals can substantially reduce diabetes-related morbidity, making the effective treatment of hyperglycaemia a high priority. By using agents that differ in their mechanism of action and side effect profiles, combination regimens can better address the numerous 


\section{Page 19 of 37}

Manuscript ID IJCP-07-10-0351.FX5

1

2

3

4

5

6

7

8

9

10

11

12

13

14

15

16

17

18

19

20

21

22

23

24

25

26

27

28

29

30

31

32

33

34

35

36

37

38

39

40

41

42

43

44

45

46

47

48

49

50

51

52

53

54

55

56

57

58

59

60

pathophysiologic abnormalities that characterise T2DM while reducing safety and tolerability issues. Combination therapy with saxagliptin and metformin provided similar $\mathrm{HbA}_{1 \mathrm{c}}$ lowering efficacy with a reduction in weight compared with weight gain and a lower proportion of hypoglycaemia vs. glipizide plus metformin. Based on this overall profile, saxagliptin plus metformin may be preferable to adding a sulphonylurea to metformin in patients with inadequate glycaemic control with metformin monotherapy. 
Manuscript ID IJCP-07-10-0351.FX5

\title{
Acknowledgements
}

This study was funded, designed and supervised by scientists at Bristol-Myers Squibb and AstraZeneca, discoverers and developers of saxagliptin. The authors gratefully acknowledge the study participants, CRAs, and site staff who assisted with this research. Technical and editorial assistance for this manuscript was provided by Jennifer Ciafullo, MPH, of Quintiles Medical Communications, Parsippany, NJ, USA.

\begin{abstract}
Author Contributions
Drs Göke, Gallwitz and Eriksson contributed to the data acquisition, drafting and critical revision of the manuscript content. Dr Gause-Nilsson and Åsa Hellqvist, MSc, contributed to the study design, data analysis/interpretation, drafting and critical revision of the manuscript content. All authors approved the final manuscript.
\end{abstract}


Manuscript ID IJCP-07-10-0351.FX5

\section{References}

1 Matthaei S, Bierwirth R, Fritsche A et al. Medical antihyperglycaemic treatment of type 2 diabetes mellitus: update of the evidence-based guideline of the German Diabetes Association. Exp Clin Endocrinol Diabetes 2009; 117: 522-57.

2 Gallwitz B, Haring HU. Future perspectives for insulinotropic agents in the treatment of type 2 diabetes-DPP-4 inhibitors and sulphonylureas. Diabetes Obes Metab 2010; 12: 1-11.

3 Nathan DM, Buse JB, Davidson MB et al. Medical management of hyperglycemia in type 2 diabetes: a consensus algorithm for the initiation and adjustment of therapy: a consensus statement of the American Diabetes Association and the European Association for the Study of Diabetes. Diabetes Care 2009; 32: 193-203.

4 Barnett A. DPP-4 inhibitors and their potential role in the management of type 2 diabetes. Int J Clin Pract 2006; 60: 1454-70.

5 Stratton IM, Adler AI, Neil HA et al. Association of glycaemia with macrovascular and microvascular complications of type 2 diabetes (UKPDS 35): prospective observational study. BMJ 2000; 321: 405-12.

6 Donath MY, Ehses JA, Maedler K et al. Mechanisms of $\beta$-cell death in type 2 diabetes. Diabetes 2005; 54: S108-S113.

7 Butler AE, Janson J, Bonner-Weir S, Ritzel R, Rizza RA, Butler PC. $\beta$-Cell deficit and increased $\beta$ cell apoptosis in humans with type 2 diabetes. Diabetes 2003; 52: 102-10.

8 Turner RC, Cull CA, Frighi V, Holman RR, UK Prospective Diabetes Study (UKPDS) Group. Glycemic control with diet, sulfonylurea, metformin, or insulin in patients with type 2 diabetes mellitus: progressive requirement for multiple therapies (UKPDS 49). JAMA 1999; 281: 2005-12.

9 UK Prospective Diabetes Study (UKPDS) Group. Intensive blood-glucose control with sulphonylureas or insulin compared with conventional treatment and risk of complications in patients with type 2 diabetes (UKPDS 33). Lancet 1998; 352: 837-53.

10 Asche CV, McAdam-Marx C, Shane-McWhorter L, Sheng X, Plauschinat CA. Association between oral and antidiabetic use, adverse events and outcomes in patients with type 2 diabetes. Diabetes Obes Metab 2008; 10: 638-45.

11 Bailey CJ, Turner RC. Metformin. N Engl J Med 1996; 334: 574-9.

12 DeFronzo RA, Goodman AM. Efficacy of metformin in patients with non-insulin-dependent diabetes mellitus. The Multicenter Metformin Study Group. N Engl J Med 1995; 333: 541-9.

13 Kahn SE, Haffner SM, Heise MA et al. Glycemic durability of rosiglitazone, metformin, or glyburide monotherapy. N Engl J Med 2006; 355: 2427-43.

14 International Diabetes Federation Clinical Guidelines Taskforce. Chapter 9: Glucose control: oral therapy. In: Global Guideline for Type 2 Diabetes. 2005; 35-8. 
15 Korytkowski MT. Sulfonylurea treatment of type 2 diabetes mellitus: focus on glimepiride. Pharmacotherapy 2004; 24: 606-20.

16 Maedler K, Carr RD, Bosco D, Zuellig RA, Berney T, Donath M. Sulfonylurea induced ß-cell apoptosis in cultured human islets. J Clin Endocrinol Metab 2008; 90: 501-6.

17 Krentz AJ, Bailey CJ. Oral antidiabetic agents: current role in type 2 diabetes mellitus. Drugs 2005; 65: $385-411$.

18 Barnett AH, Cradock S, Fisher M, Hall G, Hughes E, Middleton A. Key considerations around the risks and consequences of hypoglycaemia in people with type 2 diabetes. Int J Clin Pract. In press.

19 Amori RE, Lau J, Pittas AG. Efficacy and safety of incretin therapy in type 2 diabetes: systematic review and meta-analysis. JAMA 2007; 298: 194-206.

20 Drucker DJ. Enhancing incretin action for the treatment of type 2 diabetes. Diabetes Care 2003; 26: 2929-40.

21 Hinke SA, Kuhn-Wache K, Hoffmann T, Pederson RA, McIntosh CH, Demuth HU. Metformin effects on dipeptidylpeptidase IV degradation of glucagon-like peptide-1. Biochem Biophys Res Commun 2002; 291: 1302-8.

22 Augeri DJ, Robl JA, Betebenner DA et al. Discovery and preclinical profile of Saxagliptin (BMS477118): a highly potent, long-acting, orally active dipeptidyl peptidase IV inhibitor for the treatment of type 2 diabetes. J Med Chem 2005; 48: 5025-37.

23 Onglyza [package insert]. Princeton, NJ: Bristol-Myers Squibb/Wilmington, DE: AstraZeneca; July 2009.

24 DeFronzo RA, Hissa M, Garber AJ et al. The efficacy and safety of saxagliptin when added to metformin therapy in patients with inadequately controlled type 2 diabetes on metformin alone. Diabetes Care 2009; 32: 1649-55.

25 Jadzinsky M, Pfützner A, Paz-Pacheco E et al. Saxagliptin given in combination with metformin as initial therapy improves glycemic control in patients with type 2 diabetes compared with either monotherapy: a randomized controlled trial. Diabetes Obes Metab 2009; 11: 611-22.

26 Nauck MA, Meininger G, Sheng D, Terranella L, Stein PP. Efficacy and safety of the dipeptidyl peptidase-4 inhibitor, sitagliptin, compared with the sulfonylurea, glipizide, in patients with type 2 diabetes inadequately controlled on metformin alone: a randomized, double-blind, non-inferiority trial. Diabetes Obes Metab 2007; 9: 194-205.

27 Ferrannini E, Fonseca V, Zinman B et al. Fifty-two-week efficacy and safety of vildagliptin vs. glimepiride in patients with type 2 diabetes mellitus inadequately controlled on metformin monotherapy. Diabetes Obes Metab 2009; 11: 157-66.

28 Seck T, Nauck M, Sheng D et al. Safety and efficacy of treatment with sitagliptin or glipizide in patients with type 2 diabetes inadequately controlled on metformin: a 2-year study. Int J Clin Pract 2010; 64: 562-76. 
29 Matthews DR, Dejager S, Ahren B et al. Vildagliptin add-on to metformin produces similar efficacy and reduced hypoglycaemic risk compared with glimepiride, with no weight gain: results from a 2-year study. Diabetes Obes Metab. In press.

30 Gulliford M, Latinovic R. Mortality in type 2 diabetic subjects prescribed metformin and sulphonylurea drugs in combination: cohort study. Diabetes Metab Res Rev 2004; 20: 239-45.

31 Kahler KH, Rajan M, Rhoads GG et al. Impact of oral antihyperglycemic therapy on all-cause mortality among patients with diabetes in the Veterans Health Administration. Diabetes Care 2007; 30: $1689-93$.

32 Johnson JA, Majumdar SR, Simpson SH, Toth EL. Decreased mortality associated with the use of metformin compared with sulfonylurea monotherapy in type 2 diabetes. Diabetes Care 2002; 25: $2244-8$.

33 Evans JM, Ogston SA, Emslie-Smith A, Morris AD. Risk of mortality and adverse cardiovascular outcomes in type 2 diabetes: a comparison of patients treated with sulfonylureas and metformin. Diabetologia 2006; 49: 930-6.

34 Rao AD, Kuhadiya N, Reynolds K, Fonseca VA. Is the combination of sulfonylureas and metformin associated with an increased risk of cardiovascular disease or all-cause mortality? Diabetes Care 2008; 31: 1672-8.

35 Fisman EZ, Tenenbaum A. A cardiologic approach to non-insulin antidiabetic pharmacotherapy in patients with heart disease. Cardiovasc Diabetol 2009; 8: 38.

36 Tzoulaki I, Molokhia M, Curcin V et al. Risk of cardiovascular disease and all cause mortality among patients with type 2 diabetes prescribed oral antidiabetes drugs: retrospective cohort study using UK general practice research database. BMJ 2009; 339: b4731.

37 Frederich R, Alexander JH, Fiedorek FT et al. A systematic assessment of cardiovascular outcomes in the saxagliptin drug development program for type 2 diabetes. Postgrad Med 2010; 122: 16-27.

38 Kothny W, Gimpelewicz C, Byiers S, Mills D, Fitchet M. Cardiovascular safety profile of vildagliptin, a new DPP-4 inhibitor for the treatment of type 2 diabetes. EASD Proceedings 2008. Diabetologia 2008; 51(suppl 1): 1 .

39 Williams-Herman D, Round E, Swern A. Safety and tolerability of sitagliptin, a selective DPP-4 inhibitor, in patients with type 2 diabetes: pooled analysis of 6139 patients in clinical trials for up to 2 years. Diabetologia 2008; 51(suppl 1): 1.

40 Williams-Herman DE, Round E, Swern AS et al. Safety and tolerability of sitagliptin in patients with type 2 diabetes: a pooled analysis. BMC Endocr Disord 2008; 8: 1-16.

41 Phung OJ, Scholle JM, Talwar M, Coleman CI. Effect of noninsulin antidiabetic drugs added to metformin therapy on glycemic control, weight gain, and hypoglycemia in type 2 diabetes. JAMA 2010; 303: 1410-8. 
Manuscript ID IJCP-07-10-0351.FX5

\section{APPENDIX}

\section{D1680C00001 Study Investigators:}

Finland: J. Eriksson, T. Hellsten, J. Hopsu, V. Kallioniemi, J. Kiesilä, S. Kurl, P. Matsi, R. Siren, J. Strand, J. Tervo; Germany: T. Block, T. Forst, H. Frick, B. Gallwitz, F. Kanniess, G. Klausmann, C. Kosch, B. Lacner, J. Menne, S. Mindt-Prüfert, B. Möckesch, M. Orlowski, A. Preusche, E. D. Schulze, W. Sehnert, J. Wachter, B. Winkelmann; Great Britain: M. Angus, D. A. Black, B. Bodalia, V. Brown, M. Butler, I. Caldwell, M. Gibson, L. Hamilton, W. J. G. Keiran, B. King, J. Langan, J. Litchfield, A. Mishra, R. Pieters, J. Simpson, J. Thompson, N. V. Wyatt; Hungary: E. Dezso, M. Dudás, M. Gurzó, A. Gyimesi, C. Kerekes, Z. Kerényi, L. Korányi, E. Ladányi, J. Mészáros, K. Páll, G. Petró, F. Poór, I. Reiber, J. Takács, G. Tamás; India: G. Bantwal, J. Gupta, S. Jain, P. U. Rani, S. Shah; Netherlands: I. Bierens, T. Boermans, J. H. Bonarius, A. Bots, P. Coenen, W. De Backer, R. De Vos, H. Ferguson, P. V. Leeuwen, H. Rol, A. Schilder, H. Van Mierlo, W. Veerman; Norway: O. Brunstad, S. Elle, J. Gronert, S. Gudnason, H. O. Høivik, K. Hoye, R. Johansen, K. O. Kjørlaug, E. Knoph, K. Langaker, G. Langslet, S. A. Lønning, S. Madsbu, K. Retterstøl, K. Risberg, E. Skjegstad; Republic of Korea: S. H. Baik, C. H. Chung, Y. S. Kim, H. C. Lee, M. S. Nam, I. B. Park, S. W. Park, Y. S. Park, H. S. Son; Russian Federation: M. Antsiferov, G. Arutyunov, I. Chazova, A. Dreval, A. Galyavich, E. Grineva, I. Karpova, A. Khokhlov, O. Kisliak, Z. Kobalava, S. Kotova, E. Krasilnikova, V. Kukharchuk, O. Lantseva, I. Libov, D. Neberidze, N. Nosova, M. Pavlova, D. Privalov, S. Shustov, E. Sivkova, L. Strongin, S. Tereschenko, N. Vorokhobina, E. Voychik, A. Zalevskaya, T. Zhelninova; Slovakia: I. Buganova, E. Fedurcova, D. Kuderova, I. Kurcova, O. Minarovicova, J. Rociakova, Z. Schroner, J. Strba, J. Truban; Vietnam: N. T. B. Dao, N. T. Khue. 
Manuscript ID IJCP-07-10-0351.FX5

1

2

3

4

5

6

7

8

9

10

11

12

13

14

15

16

17

18

19

20

21

22

23

24

25

26

27

28

29

30

31

32

33

34

35

36

37

38

39

40

41

42

43

44

45

46

47

48

49

50

51

52

53

54

55

56

57

58

59

60

Table 1 Demographic and baseline clinical characteristics*

\begin{tabular}{|c|c|c|}
\hline & SAXA + MET & GPZ + MET \\
\hline Characteristic & $(n=428)$ & $(n=430)$ \\
\hline Age, years, mean (SD) & $57.5(10.26)$ & $57.6(10.37)$ \\
\hline Aged $\geq 65$ years, $n(\%)$ & $106(24.8)$ & $113(26.3)$ \\
\hline Aged $\geq 75$ years, $n(\%)$ & $21(4.9)$ & $21(4.9)$ \\
\hline \multicolumn{3}{|l|}{ Gender, $n(\%)$} \\
\hline Male & $212(49.5)$ & $232(54.0)$ \\
\hline Female & $216(50.5)$ & $198(46.0)$ \\
\hline \multicolumn{3}{|l|}{ Race, $n(\%)$} \\
\hline Asian & $73(17.1)$ & $65(15.1)$ \\
\hline Black/African American & $1(0.2)$ & 0 \\
\hline White & $352(82.2)$ & $362(84.2)$ \\
\hline Other & $2(0.5)$ & $3(0.7)$ \\
\hline \multicolumn{3}{|l|}{ Geographical region, $n(\%)$} \\
\hline Asia & $68(15.9)$ & $63(14.7)$ \\
\hline Europe & $360(84.1)$ & $367(85.3)$ \\
\hline Weight, kg, mean (SD) & $88.7(18.61)$ & $88.6(19.64)$ \\
\hline BMI, $\mathrm{kg} / \mathrm{m}^{2}$, mean $(\mathrm{SD})$ & $31.5(5.70)$ & $31.3(6.17)$ \\
\hline Duration of diabetes, years, mean (SD) & $5.5(4.5)$ & $5.4(4.7)$ \\
\hline $\mathrm{HbA}_{1 \mathrm{c}}, \%$, mean $(\mathrm{SD})$ & $7.7(0.9)$ & $7.7(0.9)$ \\
\hline$<7.0 \%, n(\%)$ & $99(23.1)$ & $105(24.4)$ \\
\hline$\geq 7.0 \%$ to $<8.0 \%, n(\%)$ & $190(44.4)$ & $186(43.3)$ \\
\hline$\geq 8.0 \%$ to $<9.0 \%, n(\%)$ & $93(21.7)$ & $105(24.4)$ \\
\hline$\geq 9.0 \%, n(\%)$ & $46(10.7)$ & $34(7.9)$ \\
\hline FPG, mg/dl, mean (SD) & $163(41.2)$ & $161(39.2)$ \\
\hline MET dose, mg, mean (SD) ${ }^{\dagger}$ & $1938(484.8)$ & $1883(453.7)$ \\
\hline$\geq 1500$ to $<2000, n(\%)^{\dagger}$ & $193(45.1)$ & $209(48.6)$ \\
\hline$\geq 2000$ to $<2500, n(\%)^{\dagger}$ & $131(30.6)$ & $143(33.3)$ \\
\hline$\geq 2500$ to $<3000, n(\%)^{\dagger}$ & $66(15.4)$ & $48(11.2)$ \\
\hline$\geq 3000, n(\%)^{\dagger}$ & $37(8.6)$ & $30(7.0)$ \\
\hline Not reported, $n(\%)^{\dagger}$ & $1(0.2)$ & 0 \\
\hline
\end{tabular}

BMI, body mass index; FPG, fasting plasma glucose; GPZ, glipizide; $\mathrm{HbA}_{1 \mathrm{c}}$, glycated haemoglobin;

MET, metformin; SAXA, saxagliptin.

* Randomized analysis set.

$\dagger$ At randomization. 
Manuscript ID IJCP-07-10-0351.FX5

Table 2 Changes in efficacy variables from baseline to week 52

\begin{tabular}{|c|c|c|}
\hline Efficacy end-point (week 52) & $\begin{array}{l}\text { SAXA + MET } \\
(n=428)\end{array}$ & $\begin{array}{c}\text { GPZ + MET } \\
(n=430)\end{array}$ \\
\hline \multicolumn{3}{|l|}{$\mathbf{H b A}_{1 \mathrm{c}}(\%)^{*}$} \\
\hline$N$ & 293 & 293 \\
\hline BL mean (SE) & $7.46(0.045)$ & $7.53(0.045)$ \\
\hline Adjusted mean change from BL (SE) & $-0.74(0.038)$ & $-0.80(0.038)$ \\
\hline Mean difference vs. GPZ + MET (SE) & $0.06(0.053)$ & \\
\hline $95 \% \mathrm{CI}$ & -0.05 to 0.16 & \\
\hline \multicolumn{3}{|l|}{ FPG (mg/dl) } \\
\hline 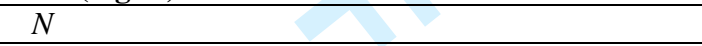 & 420 & 420 \\
\hline BL mean (SE) & $162(2.0)$ & $161(1.9)$ \\
\hline Adjusted mean change from BL (SE) & $-9(1.6)$ & $-16(1.6)$ \\
\hline Mean difference vs. GPZ + MET (SE) & $6(2.2)$ & \\
\hline $95 \% \mathrm{CI}$ & 1.7 to 10.5 & \\
\hline \multicolumn{3}{|l|}{ Fasting insulin $(\mu \mathrm{U} / \mathrm{ml})$} \\
\hline$N$ & 374 & 375 \\
\hline BL mean (SE) & $13.3(0.72)$ & $13.1(0.47)$ \\
\hline Adjusted mean change from BL (SE) & $1.0(0.54)$ & $1.2(0.54)$ \\
\hline Mean difference vs. GPZ + MET (SE) & $-0.2(0.76)$ & \\
\hline $95 \% \mathrm{CI}$ & -1.7 to 1.3 & \\
\hline \multicolumn{3}{|l|}{ Fasting C-peptide (ng/ml) } \\
\hline$N$ & 357 & 358 \\
\hline BL mean (SE) & $3.17(0.076)$ & $3.15(0.081)$ \\
\hline Adjusted mean change from BL (SE) & $0.10(0.065)$ & $0.25(0.064)$ \\
\hline Mean difference vs. GPZ + MET (SE) & $-0.15(0.091)$ & \\
\hline $95 \% \mathrm{CI}$ & -0.33 to 0.03 & \\
\hline \multicolumn{3}{|l|}{ Fasting glucagon $(\mathrm{pg} / \mathrm{ml})$} \\
\hline$N$ & 384 & 374 \\
\hline BL mean (SE) & $71.6(1.52)$ & $74.0(1.56)$ \\
\hline Adjusted mean change from BL (SE) & $1.8(1.32)$ & $6.6(1.34)$ \\
\hline Mean difference vs. GPZ + MET (SE) & $-4.9(1.88)$ & \\
\hline $95 \% \mathrm{CI}$ & -8.6 to -1.2 & \\
\hline \multicolumn{3}{|l|}{ Fasting proinsulin (pmol/l) } \\
\hline$N$ & 393 & 389 \\
\hline BL mean (SE) & $26.1(1.24)$ & $28.0(1.54)$ \\
\hline Adjusted mean change from BL (SE) & $-1.1(1.18)$ & $4.4(1.19)$ \\
\hline Mean difference vs. GPZ + MET (SE) & $-5.5(1.67)$ & \\
\hline $95 \% \mathrm{CI}$ & -8.8 to -2.2 & \\
\hline \multicolumn{3}{|l|}{$\mathrm{HbA}_{1 \mathrm{c}} \leq 6.5 \%$} \\
\hline$N$ & 423 & 423 \\
\hline$n(\%)$ & $152(35.9)$ & $145(34.3)$ \\
\hline Mean difference in proportion vs. GPZ + MET (\%) & 1.7 & \\
\hline $95 \% \mathrm{CI}$ & -4.8 to 8.1 & \\
\hline \multicolumn{3}{|l|}{$\mathrm{HbA}_{1 \mathrm{c}}$ change from $\mathrm{BL}$ with $\mathrm{BL} \mathrm{HbA}_{1 \mathrm{c}} \geq 7.0 \%$} \\
\hline$N$ & 324 & 320 \\
\hline
\end{tabular}


Manuscript ID IJCP-07-10-0351.FX5

1

2

3

4

5

6

7

8

9

10

11

12

13

14

15

16

17

18

19

20

21

22

23

24

25

26

27

28

29

30

31

32

33

34

35

36

37

38

39

40

41

42

43

44

45

46

47

48

49

50

51

52

53

54

55

56

57

58

59

60

\begin{tabular}{|c|c|c|}
\hline BL mean (SE) & $7.96(0.045)$ & $7.96(0.041)$ \\
\hline Adjusted mean change from BL (SE) & $-0.65(0.049)$ & $-0.77(0.050)$ \\
\hline Mean difference in proportion vs. GPZ + MET (SE) & $0.12(0.070)$ & \\
\hline $95 \% \mathrm{CI}$ & -0.01 to 0.26 & \\
\hline \multicolumn{3}{|l|}{$\mathrm{HbA}_{1 \mathrm{c}}<7.0 \%$ with $\mathrm{BL} \mathrm{HbA}_{1 \mathrm{c}} \geq 7.0 \%$} \\
\hline$N$ & 324 & 320 \\
\hline$n(\%)$ & $138(42.6)$ & $153(47.8)$ \\
\hline Difference vs. GPZ + MET (\%) & -5.2 & \\
\hline $95 \% \mathrm{CI}$ & -12.9 to 2.5 & \\
\hline \multicolumn{3}{|l|}{ HOMA-2及 (\%) } \\
\hline$N$ & 341 & 336 \\
\hline BL mean (SE) & $66.7(1.72)$ & $68.3(2.08)$ \\
\hline Adjusted mean change from BL (SE) & $7.4(2.54)$ & $21.7(2.56)$ \\
\hline Mean difference vs. GPZ + MET (SE) & $-14.3(3.60)$ & \\
\hline $95 \% \mathrm{CI}$ & -21.4 to -7.2 & \\
\hline
\end{tabular}

BL, baseline; CI, confidence interval; FPG, fasting plasma glucose; GPZ, glipizide; $\mathrm{HbA}_{1 \mathrm{c}}$, glycated haemoglobin; MET, metformin; SAXA, saxagliptin; SE, standard error; PPG, postprandial glucose.

*Per-protocol analysis set. $\mid v$
Deleted: PPG at $120 \min \dagger(\mathrm{mg} \ldots[1]$

Deleted: $\dagger$ Oral glucose tolerance test (OGTT) patient subset.If 
Manuscript ID IJCP-07-10-0351.FX5

Table 3 Safety and tolerability during the 52-week treatment period

\begin{tabular}{|c|c|c|}
\hline & SAXA + MET & GPZ + MET \\
\hline Adverse events, $\mathbf{n}(\%)^{*} \dagger+$ & $(n=428)$ & $(n=430)$ \\
\hline$\geq 1 \mathrm{AE}$ & $260(60.7)$ & $293(68.1)$ \\
\hline$\geq 1$ related $\mathrm{AE}$ & $42(9.8)$ & $134(31.2)$ \\
\hline Deaths & $2(0.5)$ & $2(0.5)$ \\
\hline$\geq 1 \mathrm{SAE} \$ \mathbb{I}$ & $39(9.1)$ & $32(7.4)$ \\
\hline$\geq 1$ related $\mathrm{SAE}$ & 0 & $1(0.2)$ \\
\hline Discontinuation from study medication due to AE & $18(4.2)$ & $19(4.4)$ \\
\hline Discontinuation from study medication due to SAEs & $8(1.9)$ & $8(1.9)$ \\
\hline \multicolumn{3}{|l|}{ Adverse events $(\geq 5 \%) * *$} \\
\hline Nasopharyngitis & $41(9.6)$ & $37(8.6)$ \\
\hline Diarrhoea & $22(5.1)$ & $16(3.7)$ \\
\hline
\end{tabular}

AE, adverse event; GPZ, glipizide; MET, metformin; SAE, serious adverse event; SAXA, saxagliptin. *AE defined as any new or worsening illness, sign, symptom or clinically significant laboratory test abnormality as noted by the investigator during the course of the study, regardless of the investigator's attribution of the event to study treatment.

$\dagger$ AEs are included up to the last of: 1) the last treatment day +1 day or, 2) the last visit day in the 52-week treatment period.

†Includes hypoglycaemia events.

$\S \mathrm{SAE}$ defined as an AE that was fatal, life threatening, required in-patient hospitalisation or prolonged an existing hospitalisation, resulted in persistent or significant disability or incapacity, a cancer, a congenital anomaly/birth defect, resulted in the development of drug dependency or drug abuse or was an important medical event that jeopardised the patient or required intervention to prevent a serious outcome.

ISSAEs are included up to the last of: 1) the last treatment day +30 days or 2) the last visit day +30 days in the 52-week treatment period.

$* *$ Excludes hypoglycaemia events. 
Manuscript ID IJCP-07-10-0351.FX5

Table 4 All reported hypoglycaemic events by fingerstick plasma glucose concentration during 52 -week treatment period*†

GPZ, glipizide; MET, metformin; SAXA, saxagliptin.

*Safety analysis set.

$\dagger$ Reported hypoglycaemia events is a combination of reports of either signs or symptoms consistent with hypoglycaemia or reported low glucose levels.

$\ddagger$ In patient and event incidences, a patient could contribute to more than 1 column. In event incidences, a patient could experience more than 1 event corresponding to the same column.

$\S$ Event percent $=100 *($ number of events of the column $) /$ total number of events.

IPatient percent $=100 *($ number of patients with events of the column $) / \mathrm{N}$. 
Manuscript ID IJCP-07-10-0351.FX5

\section{FIGURE LEGENDS}

Figure 1 Patient disposition. Recruitment period ran from December 11, 2007 through August 5, 2008, and the last visit in the 52-week treatment period was August 28, 2009. *The category of "No longer met study criteria" corresponds to the category of "Development of study specific discontinuation criteria." $\dagger$ Patients were only included in this category if the study investigator checked adverse event (AE) as the primary reason for discontinuation. A patient may have experienced an AE that resulted in discontinuation and was summarised as an AE leading to discontinuation that was not counted here as a reason for discontinuation if the study investigator checked an alternative primary reason for discontinuation. $\ddagger$ Per study investigator’s opinion. GPZ, glipizide; MET, metformin; SAXA, saxagliptin.

Figure 2 Composite figure. (A) Primary end-point: Adjusted mean change from baseline $\mathrm{HbA}_{1 \mathrm{c}}$ at week 52: SAXA + MET vs. GPZ + MET. (B) Mean $\mathrm{HbA}_{1 \mathrm{c}}$ values over time: SAXA + MET vs. GPZ + MET. *Per-protocol analysis set GPZ, glipizide; MET, metformin; SAXA, saxagliptin.

Figure 3 Proportion of patients with at least 1 hypoglycaemic episode over 52 weeks. *Safety analysis set. $\dagger \mathrm{p}<0.0001$.

Figure 4 Adjusted mean change from baseline body weight $(\mathrm{kg})$ to week 52 . * Safety analysis set. $\dagger \mathrm{p}<$ 0.0001 . 
Manuscript ID IJCP-07-10-0351.FX5

1

2

3

4

5

6

7

8

9

10

11

12

13

14

15

16

17

18

19

20

21

22

23

24

25

26

27

28

29

30

31

32

33

34

35

36

37

38

39

40

41

42

43

44

45

46

47

48

49

50

51

52

53

54

55

56

57

58

59

60

\section{FIGURES}

Figure 1 Patient disposition

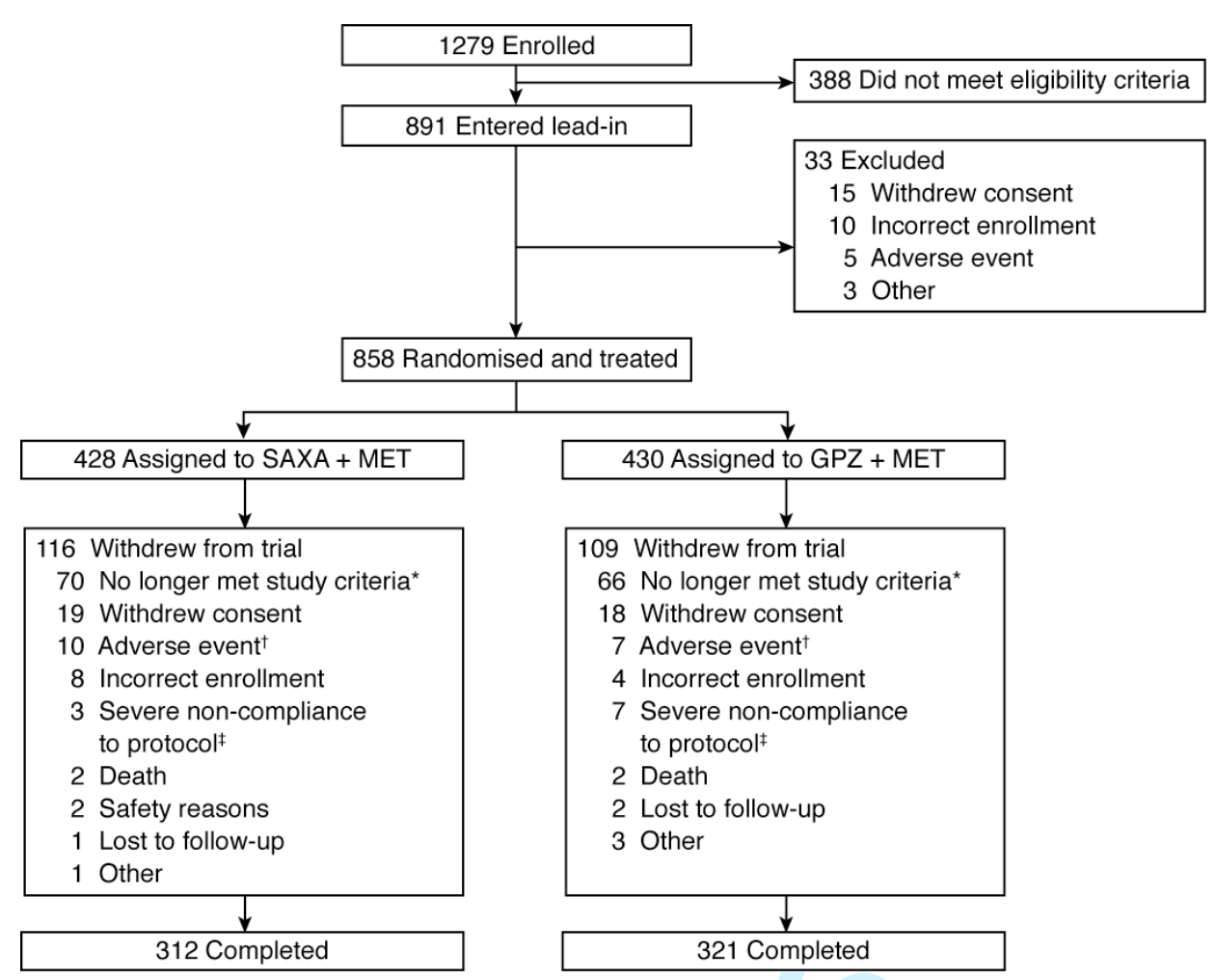


Manuscript ID IJCP-07-10-0351.FX5

Figure 2 Composite figure

(A) Primary end-point: Adjusted mean change from baseline $\mathrm{HbA}_{1 \mathrm{c}}$ at week 52*: SAXA + MET vs. GPZ + MET

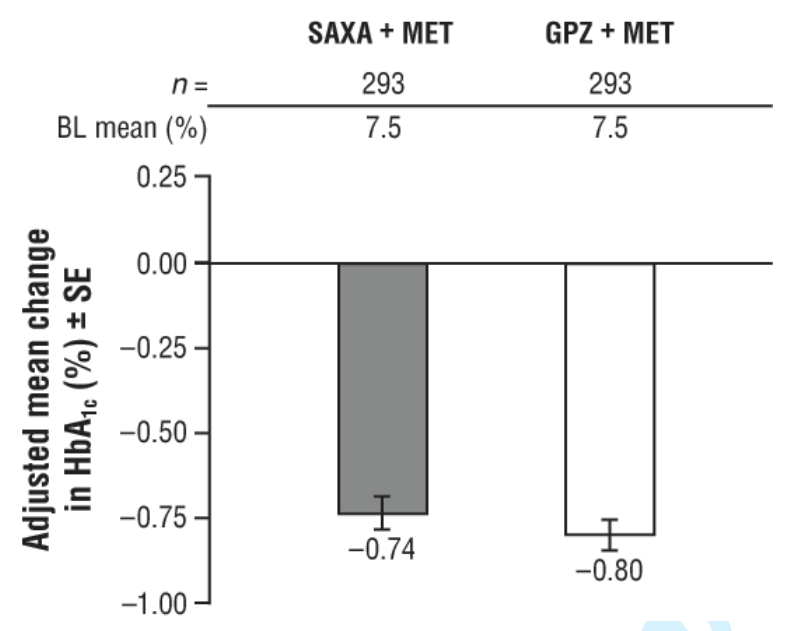


Manuscript ID IJCP-07-10-0351.FX5

1

2

3

4

5

6

7

8

9

10

11

12

13

14

15

16

17

18

19

20

21

22

23

24

25

26

27

28

29

30

31

32

33

34

35

36

37

38

39

40

41

42

43

44

45

46

47

48

49

50

51

52

53

54

55

56

57

58

59

60

(B) Mean $\mathrm{HbA}_{1 \mathrm{c}}$ values over time*: SAXA + MET vs. GPZ + MET

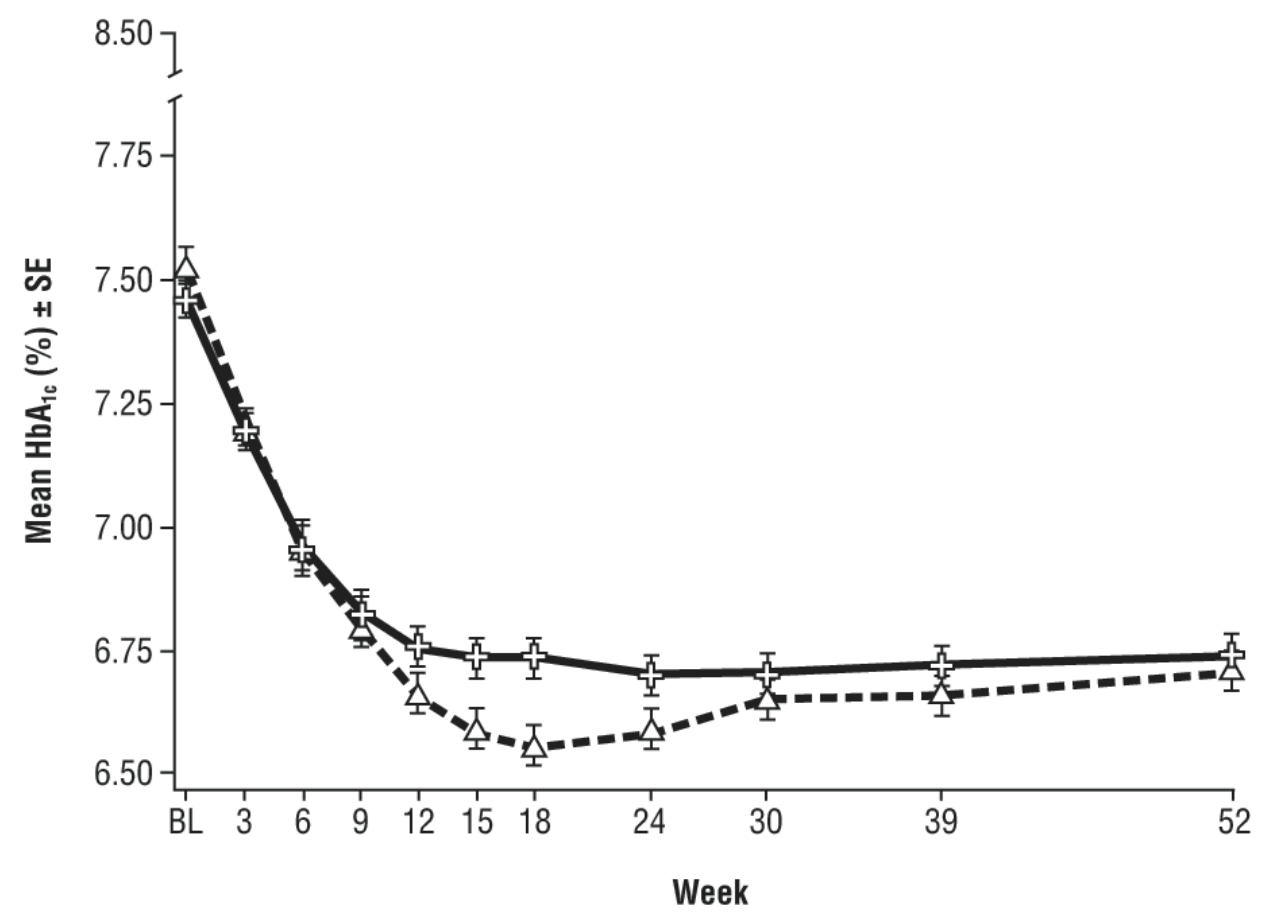

- 
Manuscript ID IJCP-07-10-0351.FX5

Figure 3 Proportion of patients with at least 1 hypoglycaemic episode over 52 weeks*

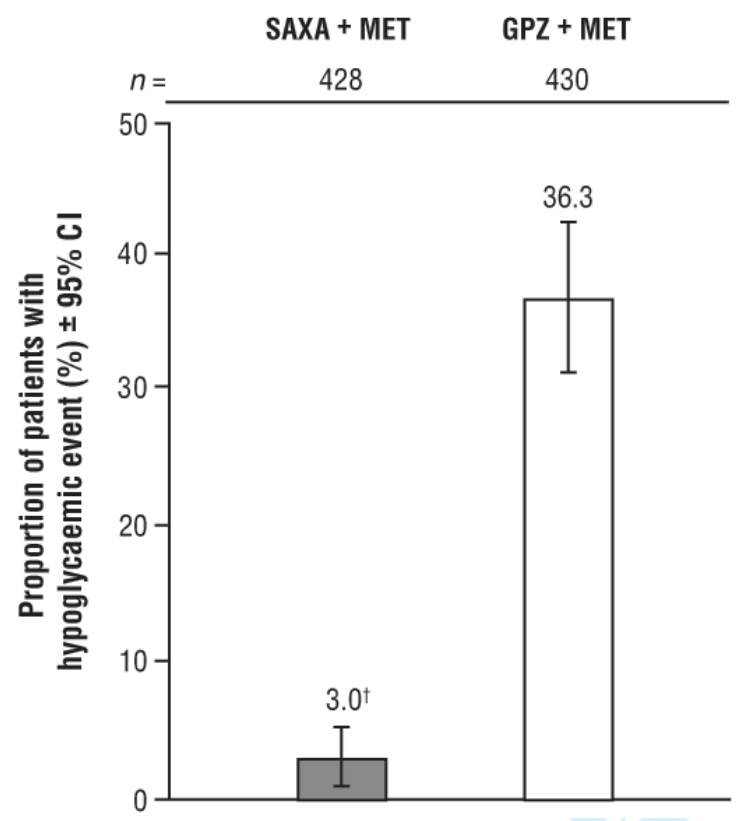


Manuscript ID IJCP-07-10-0351.FX5

1

2

3

4

5

6

7

8

9

10

11

12

13

14

15

16

17

18

19

20

21

22

23

24

25

26

27

28

29

30

31

32

33

34

35

36

37

38

39

40

41

42

43

44

45

46

47

48

49

50

51

52

53

54

55

56

57

58

59

60

Figure 4 Adjusted mean change from baseline body weight to week 52*: SAXA + MET vs. GPZ + MET

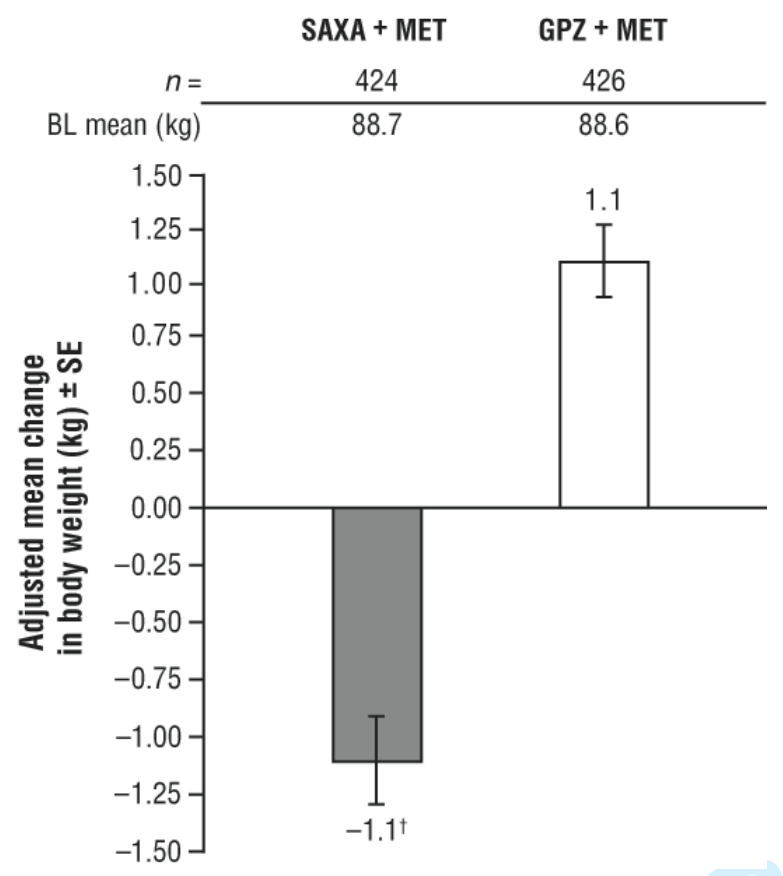


Manuscript ID IJCP-07-10-0351.FX5

\section{SUPPLEMENTARY MATERIAL}

Table 1 Conversion chart: conventional to SI units*

\begin{tabular}{|l|c|c|c|}
\hline \multicolumn{1}{|c|}{ Component } & Conventional Unit & Conversion Factor & SI Unit \\
\hline Glucose & $\mathrm{mg} / \mathrm{dl}$ & 0.0555 & $\mathrm{mmol} / \mathrm{l}$ \\
\hline Insulin & $\mu \mathrm{IU} / \mathrm{ml}$ & 6.945 & $\mathrm{pmol} / \mathrm{l}$ \\
\hline Glucagon & $\mathrm{pg} / \mathrm{ml}$ & 1.0 & $\mathrm{ng} / \mathrm{l}$ \\
\hline C-peptide & $\mathrm{ng} / \mathrm{ml}$ & 0.333 & $\mathrm{nmol} / \mathrm{l}$ \\
\hline
\end{tabular}

*To convert from the conventional unit to the SI unit, multiply by the conversion factor.

SI, Système International d'Unités. 


\begin{tabular}{|l|c|c|}
\hline Page 27: [1] Deleted & \multicolumn{2}{c}{ Quintiles } \\
\hline PPG at 120 $\mathbf{~ m i n} \dagger(\mathbf{m g} / \mathbf{d l})$ & 18 & 17 \\
\hline$N$ & $285(11.7)$ & $280(16.1)$ \\
\hline BL mean $(\mathrm{SE})$ & $-49(16.6)$ & $-28(17.1)$ \\
\hline Adjusted mean change from BL (SE) & $-21(23.8)$ & \\
\hline Mean difference vs. GPZ + MET (SE) & -69.3 to 27.8 & \\
\hline $95 \%$ CI &
\end{tabular}

